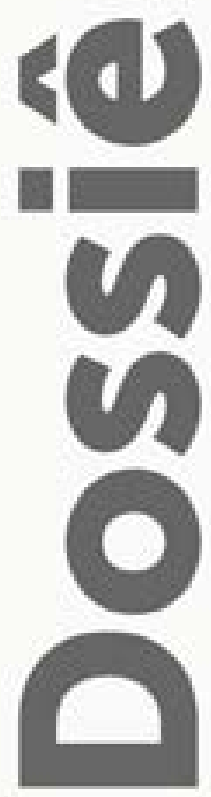

araujo.anacris@sapo.pt

\title{
Vicente Coelho de Seabra Silva Teles e a reforma dos cemitérios
}

\author{
Vicente Coelho de Seabra Silva Teles and the \\ reform of the cemeteries
}

\section{RESUMO}

Este artigo foca os aspetos práticos e os conceitos teóricos do debate sobre o ar respirável e o impacto que tais ideias tiveram na reforma dos espaços públicos, em particular dos cemitérios. As teorias químicas sobre combustão, oxidação e respiração de organismos vivos foram adotadas por Vicente Coelho de Seabra Silva Teles que as aplicou, de forma radical, à projetada reforma dos cemitérios em Portugal, no final do século XVIII. Vicente Coelho de Seabra Silva Teles foi professor de Química da Universidade de Coimbra e escreveu a Memoria sobre os prejuisos causados pelas sepulturas dos cadaveres nos templos, e methodo de os prevenir, publicada pela Casa Literária do Arco do Cego. Neste livro, discutiu as razões científicas da reforma dos cemitérios e aderiu às ideias do movimento europeu cremacionista, favoráveis à destruição física pelo fogo dos cadáveres. A voz crítica de Vicente Coelhode Seabra Silva Teles integrou-se na campanha internacional em prol da secularização das necrópoles e antecipou, com base nos conhecimentos da Química moderna, os fundamentos práticos do movimento cremacionista do séculos XIX.

Palavras-chave: Cemitérios - Higiene Pública - Vicente Coelho de Seabra Silva Teles - Cremação - Química

\begin{abstract}
This article focuses on the practical aspects and theoretical concepts of the debate on breathable air and the impact of such ideas on the reform of public spaces, particularly on the reform the cemeteries. The theories of Chemistry on combustion, oxidation and respiration of living organisms were adopted by Vicente Coelho de Seabra Silva Teles, who applied them in a radical way to the projected reform of cemeteries in Portugal, at the end of the eighteenth century. Vicente Coelhode Seabra Silva Teles was professor of the Chemistry at the University of Coimbra and he wrote the Memoria sobre os prejuisos causados pelas sepulturas dos cadaveres nos templos, e methodo de os prevenir, published by Casa Literária do Arco do Cego. In this book, he discussed the scientific reasons for the reform of the cemeteries and the ideas of the European cremation movement, which advocated the physical destruction of corpses through fire. The critical voice of Vicente Coelho de Seabra Silva Teles was integrated in the international campaign for the secularization of the necropolis and anticipated, based on the knowledge of modern Chemistry, the practical foundations of the cremationist movement of the 19th century.
\end{abstract}

Keywords: Cemeteries - Public Health - Vicente Coelho de Seabra Silva Teles - Cremation - Chemistry

* Professora Associada com agregação do Departamento de História Estudos Europeus, Arqueologia e Artes da Faculdade de Letras da Universidade de Coimbra. Doutorada em História Moderna e Contemporânea. Regente da Graduação e da Pós-Graduação em História e investigadora integrada do Centro de História da Sociedade e da Cultura (Fundação para a Ciência e a Tecnologia-FCT). CV: http://www.uc.pt/fluc/pessoal/docentes/individuais/ana_cristina_araujo 


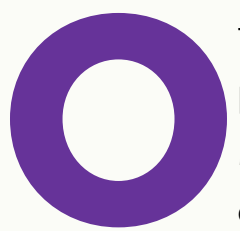

tema da localização das necrópoles no Ocidente cristão, cuja mudança foi pensada e debatida nos séculos XVIII e XIX, ocupa um lugar central na História da Morte. Partindo da constatação de que as igrejas no mundo católico se haviam convertido, ao longo das épocas medieval e moderna, em espaços saturados de vivos e mortos, Philippe Ariès documentou a razão de ser da quebra de laços entre a igreja e o cemitério, em L'Homme devant la mort (1977). Associou o movimento tendente à inumação em campo aberto nos novos cemitérios construídos fora dos centros das aldeias e cidades à secularização dos costumes cristãos e à assimilação por parte de leigos e eclesiásticos das recomendações de médicos e higienistas e enfatizou, por fim, a progressiva privatização das práticas fúnebres no século XIX. Na mesma linha, Jean-Didier Urbain utilizou a metáfora "arquipélago dos mortos", para exprimir a função simbólica dos novos cemitérios, abertos à evocação individual e familiar dos antepassados e à dissimulação do cadáver pelo mármore, colocando, assim, as necrópoles modernas no âmago da "sociedade de conservação" do século XIX (Urbain, 1989).

Mais sensível ao contexto social, religioso e cultural das Luzes e do Romantismo, Michel Vovelle explorou as angústias e resistências suscitadas pelo modo tradicional de inumação em solo sagrado, em La mort et l'Occident de 1300 à nos jours (1983). Demonstrou que, nos séculos XVIII e XIX, foi-se generalizando a convicção de que asobrevivência dos vivos impunha o saneamento do espaço dos mortos e que a limpeza dos templos convinha a um modelo de espiritualidade católica mais despojado e mais centrado, não no medo, mas na esperança salvífica dos crentes. $O$ exílio dos mortos, consentido com alguma resistência pelas igrejas, acabou por se impor, suportado sempre por considerações médicas, filosóficas e urbanísticas. $\mathrm{Na}$ área meridional europeia em que, como reconheceu Vovelle, foi mais lenta a mudança da geografia cemiterial, as evocações de tipo familiar, religioso e social instituíram no espaço público novos lugares de memória, licenciados e geridos pelas municipalidades. Segundo esta lógica, a batalha pela construção de cemitérios públicos cedo revelou as implicações políticas do problema de manter a guarda dos mortos sob controlo das instâncias que governavam os vivos, como bem explicou Fernando Catroga em Militância laica e descristianização da morte em Portugal (1988).

Desde logo, as primeiras propostas de reforma dos cemitérios no século XVIII foram correlatas da racionalidade que se pretendia imprimir ao poder político, que passou a regulamentar, de acordo com novos padrões de segurança, bem-estar e utilidade, oslocais públicos. Neste âmbito, a polícia, organismo criado para normalizar a vida social, vigiar e reorganizar os espaços públicos e disciplinar circuitos de pessoas e bens, contribuiu, efetivamente, para reforçar o poder do Estado em áreas até então ausentes das preocupações dos governos centrais. A sensibilidade às questões de salubridade, ventilação, higiene e ordenamento urbanístico, informadas por algumas evidências empíricas e crescentes medos sociais, justificaram a intervenção das políticas estatais nos domínios da assistência e da saúde públicas. Agindo em nome da felicidade geral e do bem comum, a polícia contribuiu para a criação de um "saber de Estado", servindo-se de agentes conhecedores dos debates filosóficos da época. 
Em Portugal, as propostas de reforma de políticas assistenciais e sanitárias que despertaram com a criação da Intendência Geral de Polícia, em 1760, conheceram um forte impulso durante a direção do intendente Pina Manique, como mostrou Laurinda Abreu, em Pina Manique - Um reformador no Portugal das Luzes (2013). Esta autora salientou também a importância que tiveram panfletos, livros, artigos de imprensa e memórias académicas na disseminação de assuntos relacionados com a saúde pública, relevando o impacto que a medicina e, em concreto, as disciplinas de química, nosologia e higiene acabaram tendo na modulação das estratégias da polícia em finais do século XVIII.

Neste artigo, retomamos, pontualmente, a problemática da higiene pública, relacionandoa questão dos cemitérios com o debate europeu sobre a composição química do ar e as teorias químicas sobre combustão, oxidação e respiração de organismos vivos com a atualidade das teses defendidas pelo químico e médico Vicente Coelho de Seabra Silva Teles. Este autor não só estava a par de tudo o que de mais avançado se produziu na sua época no campo da química, comoaplicou os conhecimentos desta ciência à pretendidareforma dos cemitérios em Portugal, dando à estampa, com o aval do Secretário de Estado, D. Rodrigo de Sousa Coutinho, a Memoria sobre os prejuisos causados pelas sepulturas dos cadaveres nos templos, e methodo de os prevenir, publicada pela Casa Literária do Arco do Cego. Ao ajuizar a raiz do problema, mostrava-seconsciente do desfasamento existente entre as elites cultivadas, que acreditavam na utilidade da ciência e no progresso das Luzes, eo povo católico ignorante que faziaprova de "uma piedade mal entendida".

\section{Medos e estratégias para combater as exalações mefíticas dos mortos}

A história da repulsa olfativa causada pelo enterramento dos mortos nas igrejas, particularmente evidente em meio urbano, a partir do século XVIII, teve origem num conjunto diverso de motivações de índole "científica" e social. Suportadas por observações experimentais e escassas evidências empíricas, as teorias e as fantasias de médicos, higienistas e homens de ciência alimentaram medos coletivos e fizeram despertar novas preocupações públicas. À medida que foram crescendo de tom as recomendações tendentes à conservação da saúde dos povos - na linha da campanha levada a cabo por Ribeiro Sanches, em meados do século XVIII - os fétidos odores da cidade, tolerados durante séculos a fio, tornaram-se insuportáveis para as elites esclarecidas e para a burguesia urbana (Araújo, 2000). Motivo de repulsa para narizes mais educados, os cheiros pútridos, associados às exalações mefíticas libertadas pelos enterramentos dos mortos nas igrejas, originaram estranhas reações de alarme por parte de académicos, espíritos ilustrados e governantes.

Alain Corbin explorou a lógica dos odores na sociedade europeia e reuniu abundantes testemunhos relacionados com a nova semiologia olfativa setecentista. Observou que o triunfo generalizado das ideias de tolerância religiosa e civil foi acompanhado por estranhas manifestações coletivas de intolerância, ligadas ao corpo, mais concretamente à linguagem dos sentidos e à perceção física de estados de salubridade e de insalubridade. À luz do quadro 
prescritivo da Química e da Medicina preventiva dos séculos XVIII e XIX identificou inquietantes denúncias de perigosos cheiros nos espaços habitados, privados e públicos (Corbin, 1982). No campo específico da higiene e da medicina, outros estudos mostraram que a ciência não permaneceu imune a medos e fantasias que marcaram o imaginário social da época. Em relação ao processo de decomposição química de matéria orgânica, incluindo cadáveres animais e humanos, relatos surpreendentes tanto sustentaram falsas visões, como estiveram na génese de assinaláveis descobertas científicas (Vigarello, 2001; Grmek, 1996).

Antes de Lavoisier e do reconhecimento do seu princípio de conservação da matéria, expresso na afirmação de que "na natureza, nada se cria, nada se perde, tudo se transforma", médicos e físicos experimentais procuraram, insistentemente, chegar à fórmula da composição do ar e compreender, qualitativa e quantitativamente, o comportamento deste estranho elemento da natureza. Partilhavam a ideia de que o ar era uma substância fluida elementar, pesada e elástica, ou seja, que "a fluidez do ar não gera atrito e as partes que o compõem cedem à mais pequena pressão; os corpos rodeados de ar movem-se facilmente, da mesma forma que nele se propagam sons e odores" (Locqueneux, 1997, p. 567).

Uma vez identificadas as "virtudes elásticas" do ar, admitia-se que existiam na atmosfera, em suspensão, emanações, eflúvios e substâncias diversas. A par desta composição essencial, generalizara-se também a convicção de que o ar era, por excelência, o lugar de expansão do flogístico, invisível e inflamável, sendo por esta razão indispensável à vida. A noção de flogístico, elaborada por Georg-Ernest Sthal, nos inícios do século XVIII, alicerçava-se no princípio do fogo, possibilitando a organização de um sistema coerente de reações de natureza química (Bensaude-Vincent e Stengers, 1992). Neste sistema, o ar, esse fluido insondável a que Boyle dedicou, sem êxito, muitas horas de observação, continuava a ser, ainda assim, um enorme enigma para "aeristas", higienistas e químicos. A síntese das interpretações da época é fixada por d'Alembert, para quem o ar continha uma "substância vital e singular desconhecida". Uma vez encerrado em recipiente metálico ou de vidro, mantinha-se sem alteração visível de forma e substância, "mas o mesmo não acontecia com os vapores que perdiam elasticidade expostos ao frio, ou escorriam sob a forma de gotas de água nas paredes internas de um copo, de sorte que os copos e as vasilhas que antes estavam cheias de vapores elásticos se esvaziavam". ${ }^{1}$ Conforme explicava o mesmo autor, algo de idêntico acontecia com as exalações de outros corpos expostos ao ar.

Portanto, antes mesmo de Lavoisier analisar os fenómenos orgânicos da combustão, muitas observações, centradas em reações fisiológicas e na ideia de saneamento do ar respirável, ajudaram a modificar o horizonte de reflexão da Química. Priestley, um dos grandes mentores da nova Química, dita pneumática, tentou medir a degradação do "ar comum" utilizado na respiração e a produção do "ar flogístico" (azoto, nitrogénio) e do "ar fixado" (gás ácido carbónico, dióxido de carbono) à custa do "ar vital", desflogístico (oxigénio). Apesar da sua ligação à teoria do flogístico, Priestley alimentou a pré-compreensão científica do ar como combinação

1 D'ALEMBERT, Jean le Rond et FORMEY, Johann Heintich Samuel. Air. In: DIDEROT, Denis et D'ALEMBERT, Jean le Rond. Encyclopédie ou dictionnaire raisonné des sciences, des arts et des métiers. Tome 1. Paris: s/l, 1751, p. 225. Disponível em: <http://artflsrv02.uchicago.edu/cgi-bin/philologic/getobject.pl?c.0:1000.encyclopedie0416>. Acesso em 10/07/2019. 
de gases de diferentes composições químicas. A sua conceção não anulou, todavia, a ideia tradicionalmente aceite do ar como mistura imprecisa de fumaças, enxofres, vapores aquosos, voláteis e salinos que exalavam da terra e dos corpos. Porém, as múltiplas observações levadas a cabo por ele e por outros seguidores da Química pneumática permitiram não só recolher, isolar e identificar uma série de gases, como detetar reações vitais de organismos animais expostos à ação dos mesmos gases. Em resultado das "descobertas" que se foram fazendo em torno do "ar fixado" (dióxido de carbono), do "ar inflamável" (hidrogénio), do "alcalino volátil" (amoníaco) e do "ácido sulfuroso", 2 generalizou-se a ideia de senso comum de que existiam duas grandes categorias de ares: os respiráveis e os corrompidos (Bensaude-Vincent, 1997, p. 241). Para a aferição de uns e outros, o odor tinha uma importância primacial, pois para o vulgo e para os sábios, sem distinção, a vigilância olfativa derivava da perceção imprecisa de processos mal identificados de putrefação e fermentação, que afetavam a atmosfera e eram nocivos para a saúde das populações.

\section{A campanha higienista a favor dos cemitérios públicos}

O temor de exalações mefíticas e a associação de miasmas e odores pútridos a febres, epidemias e acidentes mortais reforçavam a necessidade de se encontrarem antídotos eficazes para combater a chamada "corrupção" do ar. Por isso, os químicos, os homens de ciência e os médicos procuravam febrilmente antimefíticos que fossem capazes de debelar, ao mesmo tempo, o mau cheiro, o fedor asfixiante e o risco mórbido. A promoção de desinfetantes e/ ou desodorizantes químicos acarretou, desde logo, a vulgarização do vinagre e o recurso a fumigações diversas de plantas e especiarias - note-se que as fumigações combinavam os efeitos benéficos do fogo com a libertação, por combustão, de substâncias tóxicas desinfetantes em espaços públicos saturados e expostos a fenómenos de contágio de difícil controlo.

É também sabido que o essencial dos textos e dos debates suscitados por estas situações extremas apontava para a possibilidade de ameaça de contágio sempre que se observassem concentrações elevadas de detritos orgânicos em putrefação, com libertação de cheiros nauseabundos. Neste aspeto, a acumulação de cadáveres nas igrejas representava uma séria ameaça para os habitantes das cidades, vilas e aldeias. Compreende-se, portanto, que alguns governantes e conselheiros políticos tenham tentado encetar o saneamento desses locais infectos muito frequentados, a par da limpeza e reordenamento de outros espaços de utilidade pública, como sejam os hospitais, prisões, matadouros, praças e mercados. As igrejas, isentas de vigilância sanitária, passaram assim a integrar os planos reforma das autoridades civis e eclesiásticas, cada vez mais preocupadas com os efeitos nefastos para a saúde das populações da coabitação de vivos e mortos enterrados, em túmulos, carneiros e valas comuns no espaço sagrado.

2 Designação correspondente ao dióxido de enxofre, de acordo com a nomenclatura introduzida por Vicente Coelho de Seabra Silva Teles. Anteriormente era designado "ar ácido vitríolo" ou ar "fétido de enxofre", neste caso sulfureto de hidrogénio. Agradeço ao doutor Sérgio Rodrigues a identificação da nomenclatura científica da época e respetiva correspondência. 
Desde os longínquos tempos medievais que o solo e os altares dos templos serviam para enterrar os mortos, projetando-se a função cemiterial também para o exterior, em redor do recinto envolvente do edifício da igreja, o chamado "passus ecclesiastici". No essencial, a deposição sepulcral e tumular em recinto sagrado, dentro ou fora da igreja, visava garantir aos mortos, conforme acreditavam os vivos, a proteção dos santos patronos celestiais no caminho da salvação eterna. A garantia simbólica de identidade coletiva da comunidade cristã, fundada na comunhão de vivos e mortos, era permanentemente encenada no espaço cemiterial circunscrito pela presença do sagrado. Ainda assim, as igrejas e os seus adros não deixaram de estar na mira de médicos e higienistas.

Neste quadro, importa referir os primeiros ecos da campanha higienista em Portugal, campanha que, tendo como fulcro a questão dos cemitérios, se iniciou, em França, com a publicação, em 1743, das famosas Lettres sur les sépultures dans les églises (1743) do abade Porée (Vovelle, 1983, p. 463). Este texto fundamental para a compreensão da moderna geografia cemiterial que lentamente foi ganhando terreno na Europa, acabou por ser conhecido e discutido em Portugal, poucos anos depois da sua 1a edição, como revelam as primeiras obras de autores portugueses publicadas em defesa do saneamento das sepulturas nas igrejas (Araújo, 1997, p. 372).

O médico José Alvarez da Silva no opúsculo intitulado: Precauções Medicas contra algumas remotas consequências que se podem excitar do Terremoto de 1755 (1756), denunciou, abertamente, "o grande dano a que se expõem os homens enterrando nos templos os cadáveres". ${ }^{3}$ Sensível aos conselhos do abade Porée e leitor atento da Encyclopédie, Alvarez revelou estar também a par dos estudos médicos produzidos nas escolas de Gottïngen e de Edimburgo. Em defesa do saneamento urbano e da saúde das populações defendeu, sem receio da censura eclesiástica, a edificação, em locais ermos e arejados, de cemitérios públicos.

Ainda no rescaldo do terramoto, outro médico, António Nunes Ribeiro Sanches, dedicou um capítulo do seu Tratado da Conservação da Saúde dos Povos (1756) à questão dos cemitérios, citando avulsamente as observações e advertências do abade Porée. Com base na literatura médica e química mais avançada, Ribeiro Sanches advogou também a separação dos mortos da cidade dos vivos e a construção de cemitérios públicos em lugares ventilados, situados na periferia de grandes cidades ou no termo de pequenos aglomerados populacionais. ${ }^{4} \mathrm{O}$ sistema tradicional de inumação, indecoroso para a própria dignidade do culto - na perspetiva de Ribeiro Sanches - foi ainda objeto de pública contestação por parte do Provedor-Mor da saúde de Lisboa, Luís de Vasconcelos e Sousa que, em 1771, avançou, sem êxito, com a proposta de criação de um cemitério público em Lisboa (Araújo, 1997, p. 372), não mencionando, todavia, o percursor espaço cemiterial moderno instituído em Vila Real de Santo António, após o terramoto de 1755.

3 SILVA, José Alvarez da. Precauções medicas contra algumas remotas consequencias, que se podem excitar do terremoto de 1755. Carta que à Illustrissima e Excelentissima Senhora Dona Leonor de Tavora, Marquesa de Tavora, escreve... Lisboa: Offic. de Joseph da Costa Coimbra, 1756, p. 10.

4 SANCHES, António Nunes Ribeiro. Tratado da Conservação da Saúde dos Povos: obra util, e igualmente necessária a os magistrados, capitaens generais, capitaens de mar, e guerra, prelados, abadesssas, medicos, e pays de familia. Com hum appendix sobre os Terremotos (1756). In: Obras, vol 2. Coimbra: Imprensa da Universidade; Acta Universitatis Conimbrigensis, p. 149-363, 1966, p. 231-232. 
Os primeiros passos para a alteração da geografia cemiterial estavam dados, mas continuá-los revelar-se-ia mais difícil. Na década de oitenta, por intervenção de Pina Manique, iniciaram-se os trabalhos preparatórios para a criação de dois cemitérios modernos em Lisboa. Aconselhado pelo famoso médico Manuel Henriques de Paiva - que havia sido aluno e mestre de oficina do laboratório químico da Universidade de Coimbra - o Intendente Geral da Polícia reuniu os primeiros dados estatísticos para a elaboração de um mapa necrológico da capital portuguesa. Esse levantamento iniciou-se em 1789 e foi com base nas prospeções então realizadas que Pina Manique encomendou aos higienistas Inácio Tamagnini e Manuel Luís Alvares de Carvalho a escolha dos terrenos apropriados para as novas construções. Em resultado dessa consulta, o decreto de 5 de Abril de 1796 previa, para o efeito, a aquisição de dois espaços, um em Campo de Ourique (Prazeres) e outro na Penha de França (Alto de S. João). Entretanto, ocorreram encerramentos temporários de espaços de inumação na capital portuguesa e iniciaram-se as inspeções a alguns cemitérios conventuais e paroquiais urbanos, medidas que virão a ser retomadas no início do século XIX, por motivo de propagação de contágios e por suspeita de mortes por inalação de gases saídos das sepulturas (Araújo, 1997, p. 372-381; Dias, 1963, p. 80-83). Enfim, as medidas pontuais, os projetos e os planos gizados no último quartel do século XVIII revelar-se-iam, com passar dos anos, indispensáveis, embora persistissem, quase sempre agravados por preconceitos de natureza mágico-religiosa, outros bloqueios à reforma dos cemitérios (Catroga, 1999, p. 42-48).

Em Portugal, a Junta da Saúde, criada em 28 de agosto de 1813, tomou algumas medidas de cunho casuístico, quase sempre ditadas por queixas e situações de urgência e tentou lançar as bases de uma política simplificada e limpa de enterramentos religiosos. Em primeiro lugar, procurou abreviar o intervalo de tempo entre a morte e o enterro do cadáver, com o argumento de que desse modo se evitariam os perigos da corrupção dos ares. Proibiu, temporariamente, enterramentos em algumas igrejas e conventos mais saturados, obrigando os coveiros a remover a terra e a cavar mais fundo as fossas sepulcrais. Em situações de risco de contágio, recomendou o uso de mortalhas embebidas em ácido muriático e o transporte dos cadáveres em caixões fechados. E para que tudo se fizesse de acordo com o supremo interesse da saúde pública, uma portaria de 9 de agosto de 1814 obrigou as entidades sanitárias a emitir certidões de óbito e a autorizar o enterro (Araújo, 1997, p. 377).

De forma menos ambiciosa, algumas câmaras promoveram medidas avulsas tendentes a criar cordões sanitários em situações extremas de contágio. Em 1798, o conde de Resende propôs que a câmara municipal do Rio de Janeiro, mediante parecer de uma reputada junta de médicos, tomasse medidas para remediar a insalubridade da cidade. Em relação ao Brasil, em 1801, uma carta régia do Príncipe Regente Dom João, dirigida governadores e bispos do Brasil, proibiu a enterro nas igrejas e ordenou a construção de um ou mais cemitérios, medida que não chegou a ser posta em prática, pois, antes e após a independência do Brasil, sucederam leis e posturas camarárias tendentes a impor a criação de cemitérios públicos (Reis, 1991, p. 275-276; Rodrigues, 1997, p. 91).

Apesar de se ter intensificado na imprensa a campanha a favor da secularização dos espaços cemiteriais, o impacto das teorias higienistas no mundo luso-brasileiro não foi pacífico 
nem imediato. No Brasil a lei de 1 de outubro de 1828, obedecendo à intenção de reforço do pelouro médico-sanitário das câmaras, apontou para o estabelecimento de cemitérios fora do recinto dos templos. Os conflitos suscitados pela continuada oposição à aplicação desta e de outras leis posterioresalastraram-se a várias regiões do Brasil. Na sequência dos conflitos revelados por João José Reis para a Bahia e de Claudia Rodrigues para o Rio de Janeiro, sabese que na cidade de S. Paulo, o primeiro cemitério extramuros dacidade foi inaugurado com forte contestação, em 1858. Pela mesma altura, surgiu em Porto Alegre, um cemitério colocado fora do recinto urbano, gerido pela Misericórdia, que também originou críticas e disputas de opinião (Dillmann, 2016, p. 74). No Recife e em Minas Gerais só em finais de Oitocentos se abandonou a prática de inumação nos templos (Ferreira, 2018, p. 158). Enfim, estes e outros exemplos demonstram que o processo de secularização dos cemitérios arrastou-se até finais de Oitocentos, beneficiando no período republicano da separação da Igreja e do Estado.

\section{Vicente Coelho de Seabra Silva Teles e a "Memoria sobre os prejuisos causados pelas sepulturas dos cadaveres nos templos, e methodo de os prevenir"}

Como já referimos, na viragem do século XVIII para o século XIX, e antecedendo o ressurgimento, em vésperas das Invasões Francesas, de novas propostas de edificação de cemitérios, seculares e públicos, em Lisboa, por alvará de 17 de Março de 1805 e por decreto de 21 de Setembro de 1806, Vicente Coelho de Seabra Silva Teles publicou, no ano de 1800, na Tipografia Calcográfica do Arco Cego, portanto com a proteção do ministro D. Rodrigo de Sousa Coutinho, a famosa Memoria sobre os prejuisos causados pelas sepulturas dos cadaveres nos templos, e methodo de os prevenir (1800)..$^{5}$ Este texto, claro e conciso, ampliou os termos do debate europeu sobre a nocividade das necrópoles tradicionais. Nele são evidentes as marcas dos modernos ensinamentos da Química e também as preocupações patrióticas e filantrópicas do seu autor.

Vicente Coelho de Seabra Silva Teles fez parte da brilhante geração universitária que ideou formar, em Coimbra, uma Sociedade Patriótica destinada a promover o bem público e a difundir os progressos das ciências, a que pertenceu também Manuel Henriques de Paiva (Araújo, 2017, p. 99-101). Ambos se formaram em Filosofia Natural e Medicina, tendo Vicente de Seabra, depois de publicar o primeiro volume de os Elementos de Chimica, em 1788, obtido o doutoramento na primeira daquelas Faculdades. Os dois volumes do Elementos de Chimica

\footnotetext{
5 Vicente Coelho de Seabra Siva Teles (1764-1804), natural Congonhas do Campo (São Paulo, Brasil), era filho do alferes Manuel Coelho Rodrigues e de sua mulher, Josefa de Ávila e Figueiredo. Depois de completar os estudos elementares e preparatórios no Brasil, matriculou-se nos cursos de Matemática e Filosofia (16/10/1783) e de Medicina (19/10/1786) na Universidade de Coimbra. Obteve os graus de Bacharel em Filosofia em 22/6/1786 e de doutor na mesma Faculdade em 13/3/1791. Quase em simultâneo, concluiu o bacharelado em Medicina em 6/7/1790 e a formatura na mesmo curso em 30/7/1791. Na Universidade de Coimbra foi demonstrador de Química (1791-1795), Metalurgia (1791-1795) e Professor substituto de Zoologia (1795-1801), Botânica (17951801) e Química (1801-1804). Foi doutorado graciosamente por carta régia de 24/1/1791. Foi eleito sócio correspondente da Academia Real das Ciências em 2/8/1789, sócio livre em 1/4/1791 e sócio efetivo da classe de Ciências Naturais em 13/1/1798. Publicou vários artigos nas Memórias da Academia Real das Ciências e algumas obras, entre as quais: Elementos de Química; oferecidos à Sociedade Literária do Rio de Janeiro para uso do seu curso de Química (2 vols.; Coimbra, 1788-1790); Dissertação sobre o calor; oferecida ao Sr. José Bonifácio de Andrada e Silva (Coimbra, 1788); Memória sobre os prejuízos causados pelas sepulturas dos cadáveres nos templos e métodos de os prevenir (Lisboa, 1800); Nomenclatura química portuguesa, francesa e latina; a que se ajusta o sistema de caracteres químicos adoptados a esta nomenclatura por Hassen, Graetz e Adet (Lisboa, 1801).
} 
marcaram a adesão de Seabra à química de Lavoisier e colocaram o seu autor a par de outros importantes homens de ciência do tempo, tais como Guyton de Morveau, Chaptal e Meusnier.

Apostado na divulgação dos mais recentes avanços da química, dedicou a obra à Sociedade Literária do Rio de Janeiro, que, na mesma altura, procurava promover a difusão e discussão das ideias das Luzes no Brasil. Vicente Coelho de Seabra Siva Teles opôs-se também "aos que querem saber tudo, e tudo querem julgar, sem nada se atreverem a escrever" conforme esclareceuno preâmbulo aos Elementos de Chimica - vindo a ocupar, por mérito próprio, o lugar de lente substituto de Química e Metalúgia, em 1793, depois de ter passado pelo Laboratório Chimico como demonstrador (Costa, 1991).

Profundo conhecedor das experiências e descobertas mais avançadas realizadas por Lavoisier, Berthollet e Fourcroy, Vicente Coelhode Seabra Siva Teles contribuiu para tornar conhecidas, em Portugal e no Brasil, as teses daqueles autores. Partilhando com Henriques de Paiva o desejo de comunicar e tornar útil o conhecimento científico, mormente em matérias tão sensíveis como a higiene e a saúde pública, reconheceuque "seria desnecessário" escrever a Memoria sobre os prejuisos causados pelas sepulturas dos cadaveres nos templos... se as luzes das Sciencias Naturaes estivessem assas espalhadas" em Portugal. ${ }^{6}$

Com base em evidências empíricas reveladas pela ciência química, denunciou a "piedade mal entendida" de párocos e crentes e a consequente transformação de "lugares santos" em espaços "pavorosos e impuros" e focos visíveis de "inumeráveis doenças". 7 Estava ciente de que era preciso ultrapassar superstições, preconceitos e crenças mal interpretadas, os quais, em seu entender, estavam na origem das más condições de vida dos povos, expostos a fontes de contaminação permanentes nas igrejas. Neste sentido, insistiu na urgência de reconversão dos espaços cemiteriais e na mudança de costumes religiosos, de modo a afastar os vivos dos miasmas mefíticos que exalavam da decomposição dos cadáveres. Aconselhou que os templos tivessem "hum grande numero de portas, e de maneira que possão ser bem arejados, e ventilados com todos os ventos" e que as sepulturas fossem "assaz profundas, e não somente de 5 até 6 palmos, como he costume". ${ }^{8}$ Um dos meios que propôs para erradicar a promiscuidade fétida dos templos implicava a construção de cemitérios fora das povoações em zonas altas e em terrenos "barrento(s), ou misturado(s) com alguma arêa, ou terra calcarea". Como já foi salientado, o autor partia do princípio de que "as terras que serviam de sepulturas se encontravam infectadas". Logo, no imediato, "não haveria outra solução (no entender de Vicente Coelho), se não a de retirá-las do local onde se encontravam (em templos religiosos) e depositá-las numa espécie de cemitério geral" (Ferreira, 2018, p. 53).

No início do Oitocentos, as regras ditadas pela Polícia sobre higiene e limpeza dos espaços públicos não passavam de meros paliativos e estavam longe de alterar a prática de sepultamento nas igrejas. Para reforçar a mensagem de Vicente de Seabra Silva Teles, José Correia Picanço veio a lume com outro texto de combate à prática dos enterramentos das

6 TELES, Vicente Coelho de Seabra da Silva. Memoria sobre os prejuizos causados pelas sepulturas dos cadaveres nos templos e methodos para os prevenir. Lisboa: Officina da Casa Litteraria do Arco do Cego, 1800, p. 3.

7 Idem, p. 2.

8 Idem, p. 21.

9 Idem, p. 23. 
igrejas.

Correia Picanço, que fora lente de Anatomia da Universidade de Coimbra e doutor pela Faculdade de Medicina de Montpellier, traduziu, em 1812, já no Brasil, para onde se deslocara em 1807, o célebre tratado de Scipione Patiolli, Staggio intorno al luogo del seppelire, a partir da versão francesa de Vicq d'Azyr. A tradução de Picanço, com o título Ensaio sobre o perigo das sepulturas nas cidades e seus contornos, conheceu a luz do prelo no Rio de Janeiro, tendo sido publicada pela impressão Régia. Gozando da proteção do príncipe D. João, este académico preocupou-se também com a formação dos médicos e cirurgiões brasileiros. Por sua indicação e com o concurso de outros clínicos foram ciadas, em 1808, a Escola Cirúrgica do Hospital Militar de Salvador e a Escola de Anatomia Cirúrgica e Médica, no Rio de Janeiro. No Brasil, o debate público em torno das causas das doenças e da morbilidade provocadas por questões ambientais e falta de higiene mobilizou também a atenção de outras figuras importantes, como Joaquim Marreiros, António Joaquim Medeiros e Bernardino António Gomes. Segundo a sintética observação deste último, as frequentes moléstias e epidemias que grassavam na cidade do Rio de Janeiro bem como os picos de mortalidade a que a cidade estava exposta derivavam do clima quente e húmido que favorecia "a putrefação das substâncias animais e vegetais, em consequência da origem dos miasmas produzidos". ${ }^{10}$

De forma mais enfática, Vicente de Seabra Silva Teles fazia notar que as leis da Química facilitavam a adoção das medidas corretas para sanear os cemitérios. Neste ponto, as reflexões do homem de ciência convergiam com as teses higienistas de Ribeiro Sanches e de Vicq d'Azyr e adensavam-se com a recordação próxima de ocorrências de contágios e acidentes mortais em cemitérios localizados no Porto e nas imediações da cidade de Coimbra. Deles dava testemunho na primeira pessoa: "referirei somente", diz Vicente de Seabra, "a grande epidemia acontecida na cidade do Porto, não ha muitos annos, e causada pela emanação podre da Igreja de Santo Ildefonso, em que, para ser destruída a dita emanação foi preciso ter muito tempo as portas abertas de noute, e de dia com sentinelas ao pé, queimar vinagres, lava-la etc. etc.". ${ }^{11}$ Registava também uma outra epidemia no Porto, em 1779, causada pela libertação de gases mefíticos da igreja dos Orfãos e mencionava que, por volta de 1795, todas as povoações da margem esquerda do Mondego, do Amial até Verride, haviam sido atingidas por "uma febre podre". Nessa ocasião e com algum dramatismo, acrescentava o que se passara consigo:

eu estive quase sendo vítima, e serião povoações inteiras, se não fosse a suma caridade e sabias Providencias do Excelentissimo Bispo Conde; da qual não pude descobrir outra origem senão a igreja de Alfarelos, assás immunda, e indecente; em cujo lugar apparecêrão os primeiros inficcionados. ${ }^{12}$

Não sabemos, em concreto, a cronologia e a natureza das medidas de "saúde pública" - a expressão é sua - adotadas na última localidade mencionada, por iniciativa do reitor da

10 O Patriota, 1813, I, 2, 57. Para mais informação, vide Kury (2007, p. 167 e ss).

11 Teles, 1800, p. 12.

12 Idem, p. 13. 
Universidade e bispo conde de Arganil, embora admitamos que a par do arejamento e do recurso a fumigações nos sítios afetados se tenha ainda procedido à renovação de terras nos locais de inumação. ${ }^{13}$ Esta era, de resto, uma das práticas mais correntes nos países em que se iniciara a "revolução dos cemitérios", França e Áustria, e que Vicente de Seabra recomendava na Memoria sobre os prejuisos causados pelas sepulturas dos cadaveres nos templos... para obviar ao tradicional costume de se empilharem cadáveres em fossas a pouca profundidade e em grande quantidade, com evidentes danos para a sanidade dos espaços sagrados e para a qualidade do ar respirável nos templos.

Conhecedor, conforme explicitou em vários escritos, dos "progressos espantosos" da "Chimica moderna", Vicente de Seabra propôs-se examinar, na referida Memória, os seguintes aspectos: "os elementos dos corpos organizados; as substâncias em que se resolvem depois de mortos; o efeito dellas sobre a economia animal; o seu estado dentro dos templos; e o meio para evitar os seus efeitos". ${ }^{14}$

$\mathrm{Na}$ esteira das conceções de Lavoisier sobre a combustão, oxidação e respiração e tirando especialmente partido da análise de Berthollet sobre os gases libertados em processos de putrefação, Vicente de Seabra começou por afirmar que "o carbónico, oxygenio, azoto e hydrogenio, combinados em diversas porções, dão origem a todas as partes dos entes organisados e que os animaes differencião-se dos vegetaes pela maior copia de azoto, acido phosporico e cal nelles sempre existentes". ${ }^{15}$

Mais adiante, insistindo na composição química de base de todos os corpos naturais e no efeito de degradação, morte e nascimento dos seres vivos deixou subentendida a sua adesão ao principio de Lavoisier, preferindo, em todo o caso, citar Beccher que tivera a intuição desse movimento ininterrupto e cíclico e que o plasmara na expressão "circulus aeterni motus", lema igualmente retomado por Fourcroy no Système des Coinnaissances Chimiques et de leurs applications aux phénomènes de la nature et de l'art (1801).

Vicente de Seabra Silva Teles era muito claro ao afirmar que não havia distinção na composição da matéria viva e não viva, rejeitando, claramente, o vitalismo. Em síntese, admitia que

os animaes pela podridão se resolvem nos seus elementos, cuja maior parte entra em novas combinações, de que resultão o amoníaco, a emanação putrida, o gaz acido carbonico [dióxido de carbono], gaz hydrogenio, gaz azótico, acido nítrico, phosphato de cal [fosfato de cálcio], e de soda [sódio], carbonico e materias oleosas. ${ }^{16}$

Destes produtos uns eram fixos e outros voláteis, sendo manifesta, conforme demonstrou, a perigosidade do "gaz acido carbónico", "invisível" e "duas vezes mais pesado que o ar puro, (oxigénio)". ${ }^{17}$ Acrescentava ainda que este gás não inflamável misturado com oxigénio

\footnotetext{
${ }^{13}$ Em abono desta hipótese regista este precedente: "entre nós se fez a renovação das terras das sepulturas da Igreja da Ordem III de S. Francisco do Convento de Jesus da cidade de Lisboa" (Teles, 1800, p. 30).

14 Teles, 1800, p. 3.

15 Idem, p. 3-4.

${ }^{16}$ Idem, p. 11.

${ }^{17}$ Idem, p. 14. Atualmente sabemos que o dióxido de carbono é cerca de 7/5 mais pesado do que o oxigénio.
} 
produzia efeitos mortíferos, efeitos comprovados por inúmeras experiências e ocorrências descritas na literatura científica. Quando ao gás acido carbónico se associava outro principio assaz nocivo, isto é, a "emanação pútrida", formando mortíferas concentrações de gases e odores para a saúde pública, os cientistas, em sua opinião, estavam eticamente obrigados a denunciar essas situações.

Identificandoo luxo e a pompa fúnebre com o modelo de anquilosada piedade católica, que ainda vigorava em Portugal, Vicente Coelho de Seabra Silva Teles sustentou que os efeitos devastadores dos cemitérios "serião irremediáveis se a Philosophia Natural, a quem a Humanidade deve tantos auxilios, não nos sugerisse os meios de evitallos, ou ao menos de diminuillos". 18

Vicente de Seabra, mesmo sabendo que a "sensação do olfato" não podia medir-se nem padronizar-se, não deixou de considerar a potencial perigosidade dos eflúvios pútridos. Dito de outro modo, sabia que os odores escapavam às malhas da linguagem científica, embora Fourcroy tivesse afirmado, em 1798, que o odor deriva da dissolução do corpo odorante no ar ou num líquido, ou seja, dependia da particular volatilidade e solubilidade de cada substância. De acordo com estes desenvolvimentos da Química, desvalorizou o olfato como fator isolado de avaliação do pútrido, reduzindo a sensação de cheiro a simples indicador da qualidade respirável do ar.

Apesar de estar em perfeita sintonia com tantas e tão espantosas descobertas, Vicente Coelho de Seabra Silva Teles não deixava de avaliar, com enorme realismo, a resistência às suas ideias em matéria de reforma dos cemitérios. A este propósito escrevia: "Não nos resta pois outro partido senão sujeitar-nos á opinião publica que somente o tempo e as circunstancias podem mudar". ${ }^{19}$

O que propôs então Vicente Coelho de Seabra Silva Teles para contrariar os danos causados pelos cemitérios tradicionais? As ideias que elaborou para resolver a questão cemiterial deliniaram três caminhos historicamente possíveis.

Em primeiro lugar, advogou a "destruição dos cadáveres antes que apodreção", 20 com destruição dos mesmos cinzas. Em segundo lugar, aconselhou a "construção de grandes e espaçosos cemitérios fora das povoações, quanto for possível, em sítios que possão ser bem lavados dos ventos e humedecidos pelas chuvas". ${ }^{21}$ Por fim, propôs o saneamento das igrejas, prevendo a neutralização química de despojos depositados em covas e sepulturas situadas intramuros e extramuros. ${ }^{22}$ As suas preferências, incluindo a cremação, anteciparam em mais de um século as propostas que, a custo, acabaram por vingar na sociedade portuguesa. ${ }^{23}$

\section{Considerações finais}

\footnotetext{
Idem, p. 22

9 Idem, p. 25

20 Idem, p. 23

21 Idem, ibidem.

22 Idem, p. 22.

23 Idem, ibidem.
} 
Em suma, Vicente Coelhode Seabra Silva Teles advogava como melhor solução para a saúde pública a destruição imediata pelo fogo dos cadáveres. ${ }^{24}$ Integrou-se assim, de forma esclarecida, no moderno movimento cremacionista europeu que teve o seu momento inaugural com Scipione Patiolli, autor de II Saggio Intorno al Luogo del Seppellire (1774), obra que Vicente Seabra bem conhecia. O seu realismo prático, em sintonia com a posição assumida por outos homens de ciência da época, antecipou em mais de um século o pragmatismo e o cientismo das teses a favor da cremação no século XX (Urbain, 1989; Catroga, 1999).

Preferindo a incineração à inumação dos cadáveres, o químico português combinou, todavia, esse meio eficaz de aniquilamento dos despojos físicos com a construção de grandes cemitérios, concebidos segundo as melhores normas de higiene, onde pudessem existir sepulcros de família, espaços de conservação das cinzas dos mortos e até, em casos especiais, locais de deposição de corpos embalsamados. Por último, e como recurso para evitar "ao menos os terríveis damnos de huma tão mal entendida piedade", 25 sustentou o saneamento dos templos que serviam de necrópoles, com remoção de terras, renovação de campas, restrições ao sepultamento de cadáveres na mesma fossa, regulação de profundidade dos enterramentos e utilização de cal viva sobre os mesmos.

Este procedimento excecional de rearranjo e limpeza dos espaços tradicionais de sepultamento acabou por favorecer a resistência à reforma dos cemitérios até 1835 , ano em que Rodrigo da Fonseca Magalhães assinou os decretos de 21 de setembro e de 8 de outubro que estão na origem da criação dos primeiros cemitérios públicos em Portugal. Também no Brasil o lento e difícil o processo que conduziu à edificação de cemitérios públicos, desencadeado pelo decreto imperial de 1828, não teve melhor sorte. "Até 1850, as medidas que previam o estabelecimento de cemitérios extramuros não saíram do papel" (Rodrigues, 1997, p. 103).

De qualquer modo, as prevenções e propostas de Vicente de Seabra Silva Teles, conhecidas na época, tanto no reino como Brasil, tinham subentendida a conservação da memória dos mortos e a conquista de maior bem estar para os vivos. Ao consagrar a entrada definitiva da ciência e da política num campo outrora reservado à intervenção dos eclesiásticos, este notável homem de ciência, nascido no Brasil e formado na Universidade de Coimbra, deu maior densidade à aspiração humanitária e higienista de exílio dos mortos, pondo em evidência a utilidade social do conhecimento científico, quer na inumação dos cadáveres, quer na sua desmaterialização.

\section{Referências Bibliográficas}

ABREU, Laurinda. Pina Manique: Um Reformador no Portugal das Luzes. Lisboa: Gradiva, 2013. $484 p$.

ARAÚJO, Ana Cristina. A Morte em Lisboa: Atitudes e Representações (1700-1830). Lisboa:

24 Idem, p. 23.

25 Idem, p. 2. 
Editorial Notícias, 1997. 534p.

ARAÚJO, Ana Cristina. Medicina e Utopia em Ribeiro Sanches. In: BORGES, Anselmo; PITA, António Pedro e ANDRÉ, João Maria (Coords.). Ars Interpretandi: Diálogo e Tempo. Porto: Fundação Eng. António de Almeida, 2000, p. 35-85.

ARAÚJO, Ana Cristina. O governo da natureza no pensamento da geração universitária de finais do século XVIII: os Estatutos Literários e Económicos da Sociedade dos Mancebos Patriotas de Coimbra. In: e FONSECA, Fernando Taveira da. A Universidade Pombalina: Ciência, Território e Coleções Científicas. Coimbra: Imprensa da Universidade de Coimbra, 2017, p. 87138.

ARIĖS, Philippe. L'Homme devant la mort. Paris: Editions du Seuil, 1977. 341p.

BENSAUDE-VINCENT, Bernadettee STENGERS, Isabelle. Histoire de la chimie. Paris: La Découverte, 1992. 364p.

BENSAUDE-VINCENT, Bernadette. Chimie. In: DÉLON, Michel. Dictionnaire Européen des Lumières. Paris: PUF, 1997, p. 241- 242.

CATROGA, Fernando. Militância laica e descristianização da morte em Portugal 1865-1911. 2 volumes. Tese (Doutorado em História). Faculdade de Letras, Universidade de Coimbra, Coimbra, 1988. 1.100p.

CATROGA, Fernando. O Céu da Memória. Cemitério romântico e culto cívico dos mortos. Coimbra: Minerva, 1999. 367p.

CORBIN, Alain. Le Miasme et la Jonquille. L'odorat et l'imaginaire social (XVIII $-\mathrm{XIX}^{\mathrm{e}}$ siècles). Paris: Aubier-Montaigne, 1982. 334p.

COSTA, António M. Amorim da. Da natureza do fogo e do calor na obra de Vicente Seabra (17641804). In: Atas do Congresso "História da Universidade". Universidade(s): História, Memória, Prespectivas. Coimbra, Universidade de Coimbra, 1991, p. 137-151.

DIAS, Vitor Manuel Lopes. Cemitérios. Jazigos e sepulturas: Estudo histórico, artístico, sanitário e jurídico. Porto: Domingos Barreira, 1963. 523p.

DILLMANN, Mauro. Morte e práticas fúnebres na secularizada República: Porto Alegre, início do século XX. Jundiaí: Paco Editorial, 2016. 428p.

FERREIRA, Pâmela Campos. Da "conservação dos homens" e "decência dos santuários": os debates políticos sobre a construção dos cemitérios extramuros em Minas Gerais (1800-1858). Dissertação (Mestrado em História). Programa de Pós-Graduação em História, Universidade de Juiz de Fora, Juiz de Fora, 2018. 203p.

GRMEK, Mirko (Dir.). Histoire de la pensée médicale en Occident. Vol. 2: De la Renaissance aux Lumières. Paris: Éditions du Seuil, 1996. 376p.

KURY, Lorelai. Descrever a pátria, difundir o saber. In: (Org.). Iluminismo e Império no Brasil: O Patriota (1813-1814). Rio de Janeiro: Editora Fio Cruz, 2007, p. 141-178.

LOCQUENEUX, Robert. Gaz. In: DÉLON, Michel (Dir.). Dictionnaire Européen des Lumières. 
Paris: PUF, 1997, p. 567-569.

REIS, João José. A morte é uma festa: ritos fúnebres e revolta popular no Brasil do século XIX. São Paulo: Companhia das Letras, 1991. 360p.

RODRIGUES, Claudia. Lugares dos mortos na cidade dos vivos: Tradições e transformações fúnebres no Rio de Janeiro. Rio de Janeiro: Prefeitura da Cidade do Rio de Janeiro, 1997. 274p.

URBAIN, Jean-Didier. L'Archipel des morts: Le sentiment de la morte et les dérives de la mémoire dans les cimetières d'Occident. Paris: Librairie Plon, 1989. 358p.

VIGARELLO, Georges. História das práticas de saúde: A saúde e a doença desde a Idade Média. Lisboa: Editorial Notícias, 2001. 292p.

VOVELLE, Michel. La mort et l'Occident de 1300 à nos jours. Paris: Gallimard, 1983. 793p.

Recebido em: 02 de setembro de 2019

Aprovado em: 23 de novembro de 2019 